\title{
ORIGINAL
}

\section{Treatment strategy for successful hepatic resection of icteric liver}

\author{
Keigo Yada, M.D. Ph.D. FACS*, Yuji Morine, M.D. Ph.D. FACS*, Hiroki Ishibashi, M.D. Ph.D., \\ Hiroki Mori, M.D. Ph.D. FACS, and Mitsuo Shimada, M.D. Ph.D. FACS \\ The Department of Surgery, the University of Tokushima, 3-18-15 Kuramoto-cho, Tokushima City, Tokushima, 770-8503, Japan
}

\begin{abstract}
Background : The treatment strategy for jaundiced patients with hilar cholangiocarcinoma (HC) is not well established. In this study, we evaluate the feasibility of our perioperative protocol for jaundiced patients with HC. Methods : Twenty patients with HC who underwent hepatic resection at our institute were enrolled, and patients were divided into icteric $(n=6)$ and normal $(n=14)$ group. As a perioperative protocol, Oral administration of Inchinkoto(ICKT), steroid and nafamostat mesilate were introduced. The evaluation of functional future remnant liver(FRL) by asiaroscintigraphy, and postoperative outcomes were retrospectively compared. Results : Indocyanine green dye retention rate at 15 minutes was higher, and LHL15 values was lower in icteric group. However, in the functional evaluation of FRL, which was the sum of GSA uptake of the future FRL, there was no significant difference of LHL15 values of the remnant liver functional reserve between the two groups. As results, according to the difference of liver function, serum AST level was not different between two groups. The number of patients with postoperative morbidity in the two groups was comparable. Conclusions : Even in HC patients with icteric liver, accurate assessment of liver functional reserve and effective perioperative treatment may attribute to successful hepatectomy and favorable post-operative outcomes. J. Med. Invest. 65 : 37 - 42, February, 2018
\end{abstract}

Keywords : hilar cholangiocarcinoma, preoperative biliary drainage, inchinkoto, steroid, ascialoscincigraphy

\section{INTRODUCTION}

It has been approximately 50 years since $\mathrm{HC}$ was first reported and comprise over $60 \%$ of all cholangiocarcinomas (1-3). Hepatobiliary malignant tumors can easily invade to hepatic hilum and cause obstructive jaundice, and their prognosis remains poor. Currently, the only curative treatment for $\mathrm{HC}$ is radical surgical resection (4), though in some advanced cases, an extended hepatic lobectomy or combined resection of major vessels is needed. Although a large number of $\mathrm{HC}$ patients are jaundiced, there is no established consensus of the operative indication for the patients with icteric liver. The tumor resection for the icteric $\mathrm{HC}$ patients may be associated with increased postoperative complication (5).

To overcome these problems, several drug protocols have been introduced. Recent systematic reviews demonstrated that perioperative administration of glucocorticoids to patients undergoing liver surgery was associated with a significant reduction in overall morbidity (6). We have already reported that nafamostat mesilate stabilize the coagulant and fibrinolytic systems and significantly reduced the rate of blood transfusion during hepatic resection (7). Also, "inchinkoto (ICKT)" is one of the most commonly used Japanese "Kampo" medicine as a hepatoprotective agent for resected liver (8).

On the other hand, preoperative biliary drainage (PBD) can be a

\footnotetext{
* These authors equally contributed to this study.
}

\section{Abbreviations}

$\mathrm{HC}$ : hilar cholangiocarcinoma, $\mathrm{PBD}$ : preoperative Biliary Drainage, PTBD : percutaneous Transhepatic Biliary Drainage, ENBD : endoscopic Nasobiliary Drainage, ICKT : Inchinkoto, FRL : future remnant liver, ICGR15 : indocyanine green dye retention rate at 15 minutes, HA : hyaluronic acid, LHL15 : ratio of liver activity to heart and liver activity at 15 minutes, GSA : Tc-99m galactosyl human serum albumin, AST : aspartate aminotransferase, SPECT : single Photon Emission Computed Tomography, ROI : region of Interest feasible option to decrease postoperative complication for such cases (9). Some authors have reported that the cut-off value of serum total bilirubin to perform PBD for icteric $\mathrm{HC}$ was 2 to $3 \mathrm{mg} / \mathrm{dl}$ (10). However, a consensus on an appropriate cut-off level of total bilirubin and duration of drainage has not been established yet. Furthermore, preoperative assessment of functional liver reserve (FLR) is important in the management of HC patients. ICG has been used to evaluate FLR before hepatectomy and provides useful information for clinical decision making regarding the indications or extent of hepatic resection in patients with injured livers $(11,12)$. Although Indocyanine green dye retention rate at 15 minutes (ICGR15) has been useful, FLR may be underestimated by ICGR 15 in some patients with obstructive jaundice. Therefore, other reliable functional parameters were needed. Recently, novel tests of FLR, such as serum HA level (13-15), GSA scintigraphy (16), and interleukin levels (17), have been used to evaluate post-surgical complications. Furthermore, the correlation of LHL15 and HH15 to ICGR15 using a linear regression model and the analysis of individual liver segments by dynamic SPECT are easy and convenient methods for predicting hepatic functional reserve by GSA scintigraphy (18-21).

Therefore, our perioperative protocol for $\mathrm{HC}$ patients includes : the drugs (e.g. glucocorticoids, nafamostat mesilate and ICKT), PBD and preoperative assessment of FLR. In this paper, we study

Received for publication September 5, 2017 ; accepted October 19, 2017.

Address correspondence and reprint requests to Keigo Yada, M.D. Ph.D. FACS, The Department of Surgery, the University of Tokushima, 318-15 Kuramoto-cho, Tokushima City, Tokushima, 770-8503, Japan and Fax : +81-88-631-9698. 
about the feasibility of our peri-operative protocol for $\mathrm{HC}$ patients including the drugs, $\mathrm{PBD}$ and preoperative assessment of function in FLR using GSA scintigraphy.

\section{PATIENTS AND METHODS}

Study population and preoperative management

Between 2004 and 2010, 20 patients (12 males and 8 females) were treated for $\mathrm{HC}$ at our institute. Jaundice was defined as a serum T-Bil level $\geq 2 \mathrm{mg} / \mathrm{dl}$. Among them, 11 patients were jaundiced at the first visit, and received biliary drainage (BD) by either percutaneous transhepatic biliary drainage (PTBD) or endoscopic naso-biliary drainage (ENBD). After BD, 6 patients were still jaundiced before surgery, and patients were divided into two groups as follows, the icteric group $(n=6)$ and the normal group $(n=14)$. Adequate PBD was evident by a relief of cholangitis, and an improvement in the liver function and/or the nutritional status of the patient. In our series, blood sampling for serum biochemistry was completed 2-3 days before surgery. Enhanced computed tomography (CT) and ICGR15 was used routinely before surgery. Preoperative liver functional reserve was estimated by asiaroscintigraphy, which evaluated by Tc-99m galactosyl human serum albumin (GSA) scintigraphy, ICGR15 and serum hyaluronic acid (HA). Of these 10 patients, GSA scintigraphy for the additional liver functional reserve evaluation was introduced for evaluating the FLR of icteric liver.

Preoperative evaluation in liver functional reserve using asiaroscintigraphy

Preoperatively, the patients underwent asiaroscintigraphy as described previously (22). Briefly, the patients received $3 \mathrm{mg}$ of TcGSA (185 MBq ; Nihon Medi-Physics, Nishinomiya, Japan) as a bolus injection into an antecubital vein. Dynamic images were recorded under a large field-of-view gamma camera with a low energy, all-purpose, parallel-hole collimator centered on the liver and the precordium. Sequential digital images were acquired to an online nuclear data processor at $30 \mathrm{~s}$ /frame for the first $20 \mathrm{~min}$ after the injection. The hepatic uptake ratio of GSA (LHL15, receptor index) was calculated by dividing the liver radioactivity at 15 minutes by the heart plus liver activity at 15 minutes. Hepatic Single Photon Emission CT (SPECT) images were acquired after the dynamic study. Dynamic SPECT acquisition was performed with a circular orbit by means of dual detectors equipped with a low energy, highly resolution collimator. The acquisition time was 30 minutes (30 rotations). After calculation of the functional liver volume, a planned liver resected line was entered into each section of the trans-axial SPECT image (Fig. 2A) and the FRL volume was calculated (Fig. 2B). The functional FRL was predicted by $99 \mathrm{mTc}-\mathrm{GSA}$ was calculated by the following formula ; Remnant liver LHL15 = LHL15 x remnant liver count / whole liver count.

\section{Perioperative drug protocol}

In all patients, orally administration of Japanese kampo medicine ICKT was introduced. Particular in patients with $\mathrm{BD}$, orally bile replacement routinely performed. After biliary drainage, ICKT was orally administered $(7.5 \mathrm{~g} /$ day $)$ during perioperative period. Furthermore, preoperative steroid ( $500 \mathrm{mg} /$ body) just before surgery and intra- and 3 days post-operative nafamostat mesilate $(200 \mathrm{mg}$ / day) was administration intravenously.

\section{Surgical procedures}

All the patients underwent hepatic lobectomy with extra-hepatic bile duct resection and regional lymph nodes dissection for curative resection. At our institute, curative resection was defined as histologically negative surgical margins at the hepatic stump of the bile duct, the duodenal stump of the bile duct, and the excision surface.

\section{Statistics}

All data were expressed as the mean \pm SD. Statistical analyses were performed using the JMP statistical program (SAS Institute, Cary, NC, USA). Comparisons of the values between two groups were performed with Mann-Whitney $U$ test. The correlation coefficients were analyzed by standard Pearson correlation analysis. Statistical significance was defined as $p<0.05$.

\section{RESULTS}

\section{Patient Characteristics}

During the study period, 20 patients underwent major hepatic resection for $\mathrm{HC}$ at our institution. The baseline characteristics of the each group were outlined in Table 1 . The icteric group was comparable with the normal group with regards to age, sex, surgical procedure and preoperative serum AST level. In the icteric group, preoperative serum T-Bil, D-Bil levels were significantly higher, whereas preoperative serum albumin level was also significantly lower, compared to the normal group.

Table 1. Comparison of baseline characteristics between icteric and normal group

\begin{tabular}{lccc}
\hline Factors & $\begin{array}{c}\text { Normal liver } \\
(\mathrm{n}=14)\end{array}$ & $\begin{array}{c}\text { Icteric liver } \\
(\mathrm{n}=6)\end{array}$ & $p$-values \\
\hline Age & $74 \pm 6$ & $72 \pm 6$ & N.S. \\
Gender (Male/Female) & $9 / 5$ & $3 / 3$ & N.S. \\
Obstructive jaundice (+/-) & $5 / 9$ & $6 / 0$ & - \\
Duration of icterus (days) & $5-46$ & $15-62$ & - \\
Surgical Procedure & & & \\
(rt. Lobectomy / lt. lobectomy) & $6(\mathrm{HPD}: 1) / 8$ & $2 / 4$ & N.S. \\
AST (IL/L) & $77 \pm 70$ & $60 \pm 23$ & N.S. \\
T-Bil (mg/dl) & $1.0 \pm 0.4$ & $5.1 \pm 3.0$ & $<0.01$ \\
D-Bil (mg/dl) & $0.15 \pm 0.07$ & $2.6 \pm 2.0$ & $<0.01$ \\
ALB (mg/dl) & $3.5 \pm 0.4$ & $2.9 \pm 0.2$ & $<0.01$ \\
\hline
\end{tabular}

HPD : hepatic resection combined with pancreatoduodenectomy

\section{Evaluation of preoperative whole liver functional reserve}

Preoperative assessment of whole liver functional reserve was shown in Fig. 1. ICGR15 was significantly more increased in the icteric group compared to that in the normal group (icteric vs. normal : $33.8 \pm 23.6 \%$ vs. $10.3 \pm 3.2, p>0.05$ ). Also, LHL 15 value of the icteric group was significantly higher than that of the normal group (icteric vs. normal : $0.883 \pm 0.029$ vs. $0.930 \pm 0.023, p<0.01$ ). No significant difference was observed in serum hyaluronic acid levels between the two groups (icteric vs. normal : $99.0 \pm 53.5$ vs. $153.9 \pm 53.8)$. In other words, whole FLR was decreased in the icteric group, due to obstructive jaundice.

\section{Evaluation of future remnant functional liver reserve}

Preoperatively, 10 patients (the icteric group : $n=5$, the normal group : $n=5$ ) were evaluated with LHL 15 of future FLR by asiaroscintigraphy. Actual future remnant FLR after hepatic resection was calculated by dividing the radioactivity of the region of interest 
Fig.1A
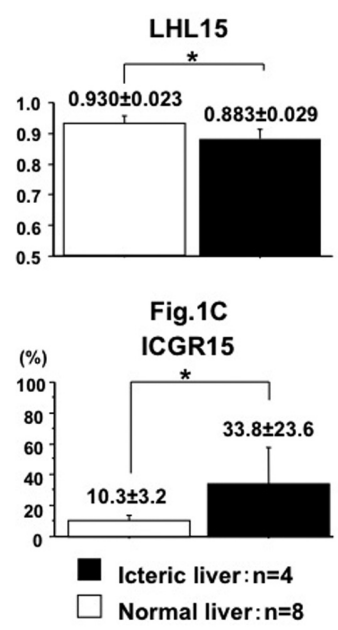

Fig.1B

Hyaluronic acid

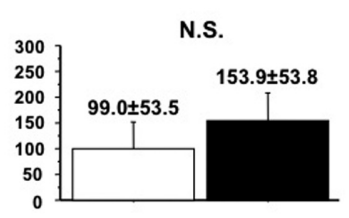

Fig.1D

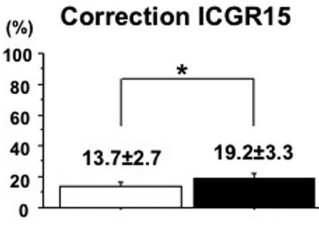

$*: p<0.05$

Figure 1

Comparison of liver functional reserve in each group.

(A) Evaluation of LHL15

(B) serum hyaluronic acid level

(C) ICGR15

(D) correction ICGR15

LHL15 was significantly higher in normal group than in icteric group $(\mathrm{p}<$ 0.05), whereas ICGR15 and correction ICGR15 were significantly higher in icteric group $(p<0.05)$. There was no significant difference between the two groups in serum HA.

(ROI) by that of the entire liver plus heart ROIs at fifteen min after the injection (Fig. 2A). As a result with calculated formula, no significant difference were observed in LHL 15 of future remnant FLR between the two groups (icteric vs. normal : $0.543 \pm 0.190 \mathrm{vs.}$ $0.503 \pm 0.159)$ (Fig. 2B).

Fig.2A

SPECT(single photon emission CT)

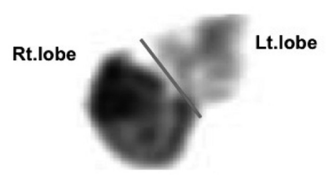

Ex.) Functional reserve of Rt. Lobe $=\mathrm{LHL} 15 \times \mathrm{R} / \mathrm{R}+\mathrm{L}$
Fig.2B

Remnant liver LHL15

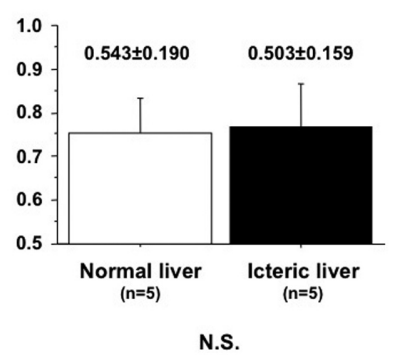

N.S.

Changes of liver injury and postoperative complication after major hepatectomy

Total bilirubin level was significantly higher in the icteric group, and remained high up to 3 weeks after surgery. On the other hand, serum AST levels showed no significant difference between two groups, and recovered normal range within 1 week in the both groups (Fig. 3).

Regarding postoperative complication, the number of patients with postoperative morbidity in the both groups were comparable (42.9\% vs. $33.3 \%$ ) (Table 2$)$.

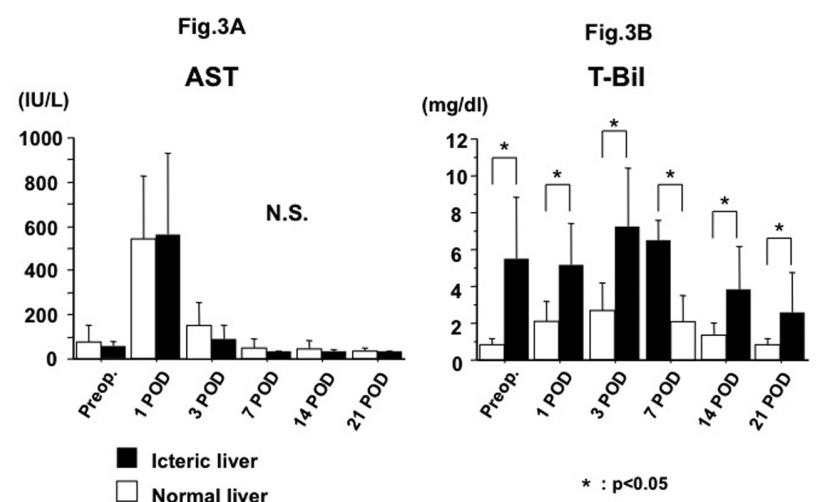

Figure 3

Post-operative course oficteric liver

(A) Post-operative changes in serum AST level

(B) Post-operative changes in serum t-bil level

Serum AST level showed no significant difference between two groups, and recovered normal range within 1 week in the both groups. Total bilirubin level was significantly higher in icteric liver group, and remained high up to 3 weeks after surgery $(\mathrm{p}<0.05)$.

Table 2. Comparison of postoperative complication between icteric and normal group

\begin{tabular}{lccc}
\hline \multirow{2}{*}{ Factors } & $\begin{array}{c}\text { Normal liver } \\
(\mathrm{n}=14)\end{array}$ & $\begin{array}{c}\text { Icteric liver } \\
(\mathrm{n}=6)\end{array}$ & $p$-values \\
\hline Post-operative complication (+/-) & $6 / 8$ & $2 / 4$ & N.S. \\
Bile leakage & 2 & 0 & - \\
Leakage (hepatico-jejunostomy) & 2 & 1 & - \\
Acute pancreatitis & 1 & 0 & - \\
Arterial bleeding & 1 & 0 & - \\
Cerebral infarction & 0 & 1 & - \\
\hline
\end{tabular}

Figure 2

Evaluation of liver functional reserve by SPECT.

(A) A cut line was entered into each section of the transaxial SPECT image.

Right LHL15 was calculated by dividing the radioactivity of the region of interest (ROI) by that of the entire liver plus heart ROIs at fifteen min after the injection.

(B) Remnant liver LHL15 were calculated.

Remnant liver LHL15 was calculated from GSA up take, and there was no significant defference between two groups.

\section{DISCUSSION}

Hepato-biliary malignant tumors easily invade to hepatic hilum, and cause invasion to main vessels and occurred obstructive jaundice. Currently, the only curative treatment for $\mathrm{HC}$ is radical surgical resection (4), but in advanced cases, an extended hepatic lobectomy or combined resection of major vessels. On the other hand, regarding to obstructive jaundice, biliary drainage has been performed to prevent liver failure and acute cholangitis. However we 
sometimes experience prolonged hyperbilirubinemia despite appropriate biliary drainage. For those reasons, the treatment strategy for $\mathrm{HC}$ patient with obstructive jaundice before surgery is not well established, and therefore major hepatic resection for icteric $\mathrm{HC}$ patient is still challenging. In this study, we demonstrated that appropriate $\mathrm{BD}$, the evaluation of $\mathrm{FRL}$, and the effective perioperative drug protocol that successfully enable the surgery for $\mathrm{HC}$ with favorable outcomes. Our important findings are as follows : 1) BD improved serum T-Bil level below $2 \mathrm{mg} / \mathrm{dl}$ in 5 of 11 patients with jaundice. 2) Although 6 patients were still jaundiced after BD, our perioperative protocol for icteric $\mathrm{HC}$ patients (e.g. preoperative drug protocol including steroids, nafamostat mesilate, ICKT and bile replacement) lead to similar short term outcome compared to non-icteric HC patients. 3) Finally, the accurate evaluation of future remnant FRL using asiaroscintigraphy was most important for achieving the successful hepatectomy without postoperative liver failure.

The usefulness of $\mathrm{BD}$ for $\mathrm{HC}$ patients remains controversial. Multiple retrospective studies have shown that BD in jaundiced $\mathrm{HC}$ patients decreases postoperative complications although no improvement in mortality or survival has been reported $(9,23-25)$. On the other hand, a systematic review comparing $\mathrm{BD}$ with no BD in resectable patients, the authors failed to note a benefit from $\mathrm{BD}$ (26). Although, randomized studies are needed to better address the potential benefits of PBD in HC, previous studies $(9,23-25,27)$ and our results suggests the benefit of $\mathrm{BD}$ for icteric $\mathrm{HC}$ patients.

Estimation of FRL is important, because $\mathrm{HC}$ patients sometimes needs extended liver surgery which may lead to postoperative hyperbilirubinemia, uncontrolled ascites, and intraabdominal infection (28). One study showed that perioperative outcomes of $\mathrm{HC}$ patients with future liver remnant volume of less than $30 \%$ was improved by BD (29). ICG has been used to evaluate FLR before hepatectomy and provides useful information for clinical decision making regarding the indications or extent of hepatic resection in patients with injured livers $(11,12)$. Although ICGR15 have been useful, in some patients with obstructive jaundice, functional liver reserve may be underestimated by ICGR15. Indeed, in our study, there was considerable dissociation in ICGR15 between the icteric and normal group. Therefore, other reliable functional parameters were needed. Recently, novel tests of FLR, such as serum HA level (13-15), GSA scintigraphy (16), and interleukin levels (17), have been used to evaluate post hepatectomy complications. Furthermore, correlation of LHL15 and HH15 to ICGR15 using a linear regression model and the analysis of individual liver segments by dynamic SPECT are easy and convenient methods for predicting FLR by GSA scintigraphy (18-21). In our study, there was no significant difference between the two groups in serum HA (Fig 1B) and remnant liver LHL15 calculated from GSA up take (Fig 2). And correction ICGR seemed to evaluate precisely icteric FLR (Fig 1D). Although several recent studies have attempted these analyses to predict complications (30-34), no distinct criteria or final consensus using these parameters have been widely accepted (35). However, GSA scintigraphy could accurately evaluate the segmental FLR, and which could be the best indicator for the decisionmaking of major hepatic resection.

Recent systematic review demonstrated that perioperative administration of glucocorticoids to patients undergoing liver surgery was associated with a significant reduction in overall morbidity, without increasing the likelihood of infectious complications and wound healing defects. In addition, steroids significantly reduced postoperative blood levels of bilirubin, and of inflammatory markers such as IL-6, and C-reactive protein whereas there is no difference in postoperative serum AST and ALT level (6, 36-41). In our study, administration of glucocorticoids may have reduced morbidity and postoperative serum bilirubin level in icteric group.

We have already reported that nafamostat mesilate stabilize the coagulant and fibrinolytic systems and significantly reduced the rate of blood transfusion in hepatic resection (7). ICKT is one of the most commonly used Japanese herbal medicines as a hepatoprotective agent. Whereas recent experiments studies have clarified the hepatoprotective effects (choleretic, anti-apoptotic, anti-inflammatory, antifibrotic and antioxidative effect) of ICKT (7, 42-48), only a few clinical studies exist that examine the benefit of ICKT in humans $(8,49)$. Among them, Watanabe et al. revealed the choleretic effect of ICKT on livers of patients with biliary obstruction due to bile duct carcinoma in Randomized Controlled trial. In our study, ICKT may be attenuated serum bilirubin level in icteric group. In our perioperative drug protocol, we have used steroids, nafamostat mesilate and ICKT. As a result, the number of patients with postoperative morbidity in the two groups was comparable.

In our summary, although major hepatectomy for the $\mathrm{HC}$ patients with icteric liver can be challenging, appropriate BD, accurate evaluation of FLR according to the each liver segment with or without biliary congestion, and effective perioperative drug protocol enable it successfully with favorable outcomes. Even in $\mathrm{HC}$ patients with icteric liver, accurate assessment of future remnant FLR and effective perioperative treatment may attribute to successful hepatectomy and favorable outcomes.

\section{CONFLICT OF INTEREST}

The authors declare no conflict of interest.

\section{ACKNOWLEDGEMENT}

This work was partly supported by Japan Society for the promotion of Science (Grants-in-Aid for Scientific Research (C) : No.20314867 and Grants-in-Aid for Young Scientists (Start-up) : No.00633893).

\section{REFERENCES}

1. Altemeier WA, Gall EA, Zinninger MM, Hoxworth PI : Sclerosing carcinoma of the major intrahepatic bile ducts. AMA archives of surgery 75(3) : 450-460 ; discussion 460-451, 1957

2. Klatskin G : Adenocarcinoma of the Hepatic Duct at Its Bifurcation within the Porta Hepatis. An Unusual Tumor with Distinctive Clinical and Pathological Features. The American journal of medicine 38 : 241-256, 1965

3. Nakeeb A, Pitt HA, Sohn TA, Coleman J, Abrams RA, Piantadosi S, Hruban RH, Lillemoe KD, Yeo CJ, Cameron JL: Cholangiocarcinoma. A spectrum of intrahepatic, perihilar, and distal tumors. Annals of surgery 224(4) : 463-473 ; discussion 473-465, 1996

4. Kondo S, Takada T, Miyazaki M, Miyakawa S, Tsukada K, Nagino M, Furuse J, Saito H, Tsuyuguchi T, Yamamoto M, Kayahara M, Kimura F, Yoshitomi H, Nozawa S, Yoshida M, Wada K, Hirano S, Amano H, Miura F : Guidelines for the management of biliary tract and ampullary carcinomas : surgical treatment. Journal of hepato-biliary-pancreatic surgery 15(1) : 41-54, 2008

5. Cherqui D, Benoist S, Malassagne B, Humeres R, Rodriguez V, Fagniez PL: Major liver resection for carcinoma in jaundiced patients without preoperative biliary drainage. Arch Surg 135(3) : 302-308, 2000

6. Orci LA, Toso C, Mentha G, Morel P, Majno PE : Systematic review and meta-analysis of the effect of perioperative steroids on ischaemia-reperfusion injury and surgical stress response in patients undergoing liver resection. The British journal of surgery 100(5) : 600-609, 2013 
7. Shimada M, Matsumata T, Shirabe K, Kamakura T, Taketomi A, Sugimachi K : Effect of nafamostat mesilate on coagulation and fibrinolysis in hepatic resection. Journal of the American College of Surgeons 178(5) : 498-502, 1994

8. Kaiho T, Tsuchiya S, Yanagisawa S, Takeuchi O, Togawa A, Okamoto R, Saigusa N, Miyazaki M : Effect of the herbal medicine Inchin-Ko-To for serum bilirubin in hepatectomized patients. Hepato-gastroenterology 55(81) : 150-154, 2008

9. Farges O, Regimbeau JM, Fuks D, Le Treut YP, Cherqui D, Bachellier P, Mabrut JY, Adham M, Pruvot FR, Gigot JF : Multicentre European study of preoperative biliary drainage for hilar cholangiocarcinoma. The British journal of surgery $100(2): 274-283,2013$

10. Xiong JJ, Nunes QM, Huang W, Pathak S, Wei AL, Tan CL, Liu $\mathrm{XB}$ : Preoperative biliary drainage in patients with hilar cholangiocarcinoma undergoing major hepatectomy. World journal of gastroenterology : WJG 19(46) : 8731-8739, 2013

11. El-Desoky A, Seifalian AM, Cope M, Delpy DT, Davidson BR: Experimental study of liver dysfunction evaluated by direct indocyanine green clearance using near infrared spectroscopy. The British journal of surgery 86(8) : 1005-1011, 1999

12. Hemming AW, Scudamore CH, Shackleton CR, Pudek M, Erb $\mathrm{SR}$ : Indocyanine green clearance as a predictor of successful hepatic resection in cirrhotic patients. American journal of surgery 163(5) : 515-518, 1992

13. Nanashima A, Yamaguchi H, Shibasaki S, Sawai T, Yamaguchi E, Yasutake T, Tsuji T, Jibiki M, Nakagoe T, Ayabe H : Measurement of serum hyaluronic acid level during the perioperative period of liver resection for evaluation of functional liver reserve. Journal of gastroenterology and hepatology 16(10) : 1158-1163, 2001

14. Nanashima A, Yamaguchi H, Tanaka K, Shibasaki S, Tsuji T, Ide N, Hidaka S, Sawai T, Nakagoe T, Nagayasu T : Preoperative serum hyaluronic acid level as a good predictor of posthepatectomy complications. Surgery today 34(11) : 913-919, 2004

15. Yachida S, Wakabayashi H, Okano K, Suzuki Y : Prediction of posthepatectomy hepatic functional reserve by serum hyaluronate. The British journal of surgery 96(5) : 501-508, 2009

16. Mitsumori A, Nagaya I, Kimoto S, Akaki S, Togami I, Takeda Y, Joja I, Hiraki Y : Preoperative evaluation of hepatic functional reserve following hepatectomy by technetium-99m galactosyl human serum albumin liver scintigraphy and computed tomography. European journal of nuclear medicine 25(10) : 1377-1382, 1998

17. Yamada T, Hisanaga M, Nakajima Y, Kanehiro H, Aomatsu Y, Ko S, Kin T, Nishio K, Sho M, Nagao M, Harada A, Matsushima $\mathrm{K}$, Nakano $\mathrm{H}$ : The serum interleukin 8 level reflects hepatic mitochondrial redox state in hyperthermochemohypoxic isolated liver perfusion with use of a venovenous bypass. Surgery 125(3) : 304-314, 1999

18. Hwang EH, Taki J, Shuke N, Nakajima K, Kinuya S, Konishi S, Michigishi T, Aburano T, Tonami N : Preoperative assessment of residual hepatic functional reserve using $99 \mathrm{mTc}-$ DTPA-galactosyl-human serum albumin dynamic SPECT. Journal of nuclear medicine : official publication, Society of $\mathrm{Nu}$ clear Medicine 40(10) : 1644-1651, 1999

19. Kawamura H, Kamiyama T, Nakagawa T, Nakanishi K, Yokoo H, Tahara M, Kamachi H, Toi H, Matsushita M, Todo S : Preoperative evaluation of hepatic functional reserve by converted ICGR15 calculated from Tc-GSA scintigraphy. Journal of gastroenterology and hepatology 23 (8 Pt 1) : 1235-1241, 2008

20. Sugahara K, Togashi H, Takahashi K, Onodera Y, Sanjo M, Misawa K, Suzuki A, Adachi T, Ito J, Okumoto K, Hattori E, Takeda T, Watanabe H, Saito K, Saito T, Sugai Y, Kawata S :
Separate analysis of asialoglycoprotein receptors in the right and left hepatic lobes using Tc-GSA SPECT. Hepatology 38 (6) : 1401-1409, 2003

21. Yamakado K, Matsumura K, Takashiba Y, Nakatsuka A, Kitano T, Ichihara T, Maeda H, Takase K, Takeda K : Binding rate constant of Tc-99m DTPA galactosyl human serum albumin measured by quantitative dynamic SPECT--clinical evaluation as a total and regional liver function test. Annals of nuclear medicine 15(3) : 191-198, 2001

22. Vera DR, Stadalnik RC, Trudeau WL, Scheibe PO, Krohn KA : Measurement of receptor concentration and forward-binding rate constant via radiopharmacokinetic modeling oftechnetium$99 \mathrm{~m}$-galactosyl-neoglycoalbumin. Journal of nuclear medicine : official publication, Society of Nuclear Medicine 32 (6) : 11691176,1991

23. Tsai HM, Chuang CH, Lin XZ, Chen CY : Factors relating to the short term effectiveness of percutaneous biliary drainage for hilar cholangiocarcinoma. World journal of gastroenterology : WJG 15(41) : 5206-5210, 2009

24. Young AL, Igami T, Senda Y, Adair R, Farid S, Toogood GJ, Prasad KR, Lodge JP : Evolution of the surgical management of perihilar cholangiocarcinoma in a Western centre demonstrates improved survival with endoscopic biliary drainage and reduced use of blood transfusion. HPB : the official journal of the International Hepato Pancreato Biliary Association 13 (7) : 483-493, 2011

25. Nuzzo G, Giuliante F, Ardito F, Giovannini I, Aldrighetti L, Belli G, Bresadola F, Calise F, Dalla Valle R, D'Amico DF, Gennari L, Giulini SM, Guglielmi A, Jovine E, Pellicci R, Pernthaler H, Pinna AD, Puleo S, Torzilli G, Capussotti L, Cillo U, Ercolani G, Ferrucci M, Mastrangelo L, Portolani N, Pulitano C, Ribero D, Ruzzenente A, Scuderi V, Federico B : Improvement in perioperative and long-term outcome after surgical treatment of hilar cholangiocarcinoma : results of an Italian multicenter analysis of 440 patients. Arch Surg 147(1) : 26-34, 2012

26. Liu F, Li Y, Wei Y, Li B : Preoperative biliary drainage before resection for hilar cholangiocarcinoma : whether or not? A systematic review. Digestive diseases and sciences 56(3) : 663672,2011

27. Iacono C, Ruzzenente A, Campagnaro T, Bortolasi L, Valdegamberi A, Guglielmi A : Role of preoperative biliary drainage in jaundiced patients who are candidates for pancreatoduodenectomy or hepatic resection : highlights and drawbacks. Annals of surgery 257 (2) : 191-204, 2013

28. Fan ST: Methods and related drawbacks in the estimation of surgical risks in cirrhotic patients undergoing hepatectomy. Hepato-gastroenterology 49(43) : 17-20, 2002

29. Kennedy TJ, Yopp A, Qin Y, Zhao B, Guo P, Liu F, Schwartz LH, Allen P, D’Angelica M, Fong Y, DeMatteo RP, Blumgart LH, Jarnagin WR: Role of preoperative biliary drainage of liver remnant prior to extended liver resection for hilar cholangiocarcinoma. $H P B$ : the official journal of the International Hepato Pancreato Biliary Association 11(5) : 445-451, 2009

30. Imamura H, Sano K, Sugawara Y, Kokudo N, Makuuchi M : Assessment of hepatic reserve for indication of hepatic resection : decision tree incorporating indocyanine green test. Journal of hepato-biliary-pancreatic surgery 12(1) : 16-22, 2005

31. Cucchetti A, Ercolani G, Vivarelli M, Cescon M, Ravaioli M, La Barba G, Zanello M, Grazi GL, Pinna AD : Impact of model for end-stage liver disease (MELD) score on prognosis after hepatectomy for hepatocellular carcinoma on cirrhosis. Liver transplantation : official publication of the American Association for the Study of Liver Diseases and the International Liver Transplantation Society 12(6) : 966-971, 2006

32. Nanashima A, Tobinaga S, Abo T, Nonaka T, Takeshita H, 
Hidaka S, Sawai T, Nagayasu T: Reducing the incidence of post-hepatectomy hepatic complications by preoperatively applying parameters predictive of liver function. Journal of hepato-biliary-pancreatic sciences 17(6) : 871-878, 2010

33. Andres A, Toso C, Moldovan B, Schiffer E, Rubbia-Brandt L, Terraz S, Klopfenstein CE, Morel P, Majno P, Mentha G: Complications of elective liver resections in a center with low mortality : a simple score to predict morbidity. Arch Surg 146(11) : 1246-1252, 2011

34. Nanashima A, Abo T, Arai J, Matsumoto H, Kudo T, Nagayasu $\mathrm{T}$ : Functional liver reserve parameters predictive for posthepatectomy complications. The Journal of surgical research 185(1) : 127-135, 2013

35. Balzan S, Belghiti J, Farges O, Ogata S, Sauvanet A, Delefosse $\mathrm{D}$, Durand $\mathrm{F}$ : The " $50-50$ criteria" on postoperative day $5:$ an accurate predictor of liver failure and death after hepatectomy. Annals of surgery 242(6) : 824-828, discussion 828-829, 2005

36. Shimada M, Saitoh A, Kano T, Takenaka K, Sugimachi K: The effect of a perioperative steroid pulse on surgical stress in hepatic resection. International surgery 81(1) : 49-51, 1996

37. Yamashita Y, Shimada M, Hamatsu T, Rikimaru T, Tanaka S, Shirabe K, Sugimachi K : Effects of preoperative steroid administration on surgical stress in hepatic resection : prospective randomized trial. Arch Surg 136(3) : 328-333, 2001

38. Muratore A, Ribero D, Ferrero A, Bergero R, Capussotti L: Prospective randomized study of steroids in the prevention of ischaemic injury during hepatic resection with pedicle clamping. The British journal of surgery 90(1) : 17-22, 2003

39. Aldrighetti L, Pulitano C, Arru M, Finazzi R, Catena M, Soldini L, Comotti L, Ferla G : Impact of preoperative steroids administration on ischemia-reperfusion injury and systemic responses in liver surgery : a prospective randomized study. Liver transplantation : official publication of the American Association for the Study of Liver Diseases and the International Liver Transplantation Society 12(6) : 941-949, 2006

40. Schmidt SC, Hamann S, Langrehr JM, Hoflich C, Mittler J, Jacob D, Neuhaus P : Preoperative high-dose steroid administration attenuates the surgical stress response following liver resection : results of a prospective randomized study. Journal of hepato-biliary-pancreatic surgery 14(5) : 484-492, 2007

41. Hayashi Y, Takayama T, Yamazaki S, Moriguchi M, Ohkubo T, Nakayama H, Higaki T : Validation of perioperative steroids administration in liver resection : a randomized controlled trial. Annals of surgery 253(1) : 50-55, 2011

42. Yamamoto M, Ogawa K, Morita M, Fukuda K, Komatsu Y : The herbal medicine Inchin-ko-to inhibits liver cell apoptosis induced by transforming growth factor beta 1 . Hepatology 23(3) : 552-559, 1996

43. Yamamoto M, Miura N, Ohtake N, Amagaya S, IshigeA, Sasaki H, Komatsu Y, Fukuda K, Ito T, Terasawa K : Genipin, a metabolite derived from the herbal medicine Inchin-ko-to, and suppression of Fas-induced lethal liver apoptosis in mice. Gastroenterology 118(2) : 380-389, 2000

44. Huang $\mathrm{W}$, Zhang J, Moore DD : A traditional herbal medicine enhances bilirubin clearance by activating the nuclear receptor CAR. The Journal of clinical investigation 113(1) : 137-143, 2004

45. Imanishi Y, Maeda N, Matsui H, Takashima T, Seki S, Arakawa T, Kawada N : Suppression of Rat Stellate Cell Activation and Liver Fibrosis by a Japanese Herbal Medicine, Inchinko-to (TJ135). Comparative hepatology 3 Suppl 1 : S11, 2004

46. Shoda J, Miura T, Utsunomiya H, Oda K, Yamamoto M, Kano M, Ikegami T, Tanaka N, Akita H, Ito K, Suzuki H, Sugiyama $\mathrm{Y}$ : Genipin enhances Mrp2 (Abcc2)-mediated bile formation and organic anion transport in rat liver. Hepatology 39(1) : 167178,2004

47. Takeuchi S, Goto T, Mikami K, Miura K, Ohshima S, Yoneyama K, Sato M, Shibuya T, Watanabe D, Kataoka E, Segawa D, Endo A, Sato W, Yoshino R, Watanabe S : Genipin prevents fulminant hepatic failure resulting in reduction of lethality through the suppression of TNF-alpha production. Hepatology research : the official journal of the Japan Society of Hepatology 33(4) : 298-305, 2005

48. Kawai K, Yokoyama Y, Kokuryo T, Watanabe K, Kitagawa T, Nagino $\mathrm{M}$ : Inchinkoto, an herbal medicine, exerts beneficial effects in the rat liver under stress with hepatic ischemiareperfusion and subsequent hepatectomy. Annals of surgery 251(4) : 692-700, 2010

49. Watanabe S, Yokoyama Y, Oda K, Kokuryo T, Shoda J, Okada $\mathrm{K}$, Utsunomiya $\mathrm{H}$, Nagino $\mathrm{M}$ : Choleretic effect of inchinkoto, a herbal medicine, on livers of patients with biliary obstruction due to bile duct carcinoma. Hepatology research : the official journal of the Japan Society of Hepatology 39 (3) : 247-255, 2009 